FAMÍLIA E COMUNIDADE

EM FOCO

\title{
PRÁtICAS COLABORATIVAS NO CALOR DE BRNO*
}

LEONORA FIGUEIREDO CORSINI ${ }^{1}$

ALEXANDRA DA ROSA MOREIRA $^{12}$

CECÍLIA CRUZ VILLARES $^{13}$

\section{HELENA MAFFEI CRUZ ${ }^{1}$}

${ }^{1}$ Instituto Noos, São Paulo/ SP, Brasil.

${ }^{2}$ Associação Paulista e Brasileira de Terapeutas de Família, São Paulo/SP, Brasil.

${ }^{3}$ Universidade Federal de São Paulo (Unifesp), São Paulo/SP, Brasil

Por Leonora Figueiredo Corsini, com a colaboração de Alexandra Moreira, Cecilia Cruz Villares e Helena Maffei Cruz. conteceu em junho deste ano, entre os dias 27 e 29, o IV Congresso de Práticas Colaborativas e Dialógicas na cidade de Brno, República Checa. $\mathrm{O}$ encontro contou com cento e oitenta participantes representando cerca de trinta e dois países. Pelo Brasil, foram apresentados doze trabalhos por vinte participantes, dentre os quais os de três integrantes da equipe de associados do Instituto Noos.

Conversamos com Cecília Cruz Villares, Helena Maffei Cruz e Alexandra da Rosa Moreira - integrantes da equipe Noos e participantes do Congresso - que generosamente compartilharam suas impressões do Congresso, cuja síntese apresentamos a seguir.

A primeira coisa a chamar atenção das três participantes foi constatar que na República Checa faz muito calor no verão! Os dias de sol e muita luz convidavam a passear para ver o movimento alegre das pessoas aproveitando a vida ao ar livre nas ruas, nos bares, nas esplanadas e nas muitas áreas verdes da simpática cidade checa. Da parte dos anfitriões checos, estes se empenharam em receber a todos com igual calor humano, possibilitando aos convidados que se sentissem felizes, ainda que quentes, dentro das salas da Universidade onde aconteceram encontros, atividades e conversas em torno de temas e projetos apaixonantes.

Como diz Cecília, sentir o clima de amizade e colaboração dos envolvidos em todos os níveis de organização do evento - da recepção ao trabalho dos tradutores e estudantes voluntários nas salas à organização das refeições, eventos sociais, passeios e visitas - permitiu às nossas representantes sentirem-se pertencentes a uma comunidade de gente disponível, feliz e orgulhosa de fazer parte de um sonho/projeto que se concretizava num evento de todos e para todos. Cecília, que ao longo de sua trajetória acadêmica já viveu a experiência de integrar comissões científicas de avaliação e seleção de trabalhos, sabe que montar um programa desse porte é sempre uma tarefa árdua, e que aceitar muitos trabalhos é a única maneira de dar espaço para projetos interessantes e oportunidade de encontros entre pessoas que não poderiam ir a um Congresso somente como participantes. Ela conhece bem o desafio de ter de escolher o que ver e participar em eventos onde há muitas atividades concorrentes. "Feito criança numa loja de guloseimas, quero tudo! Ao mesmo tempo, sinto pelos trabalhos interessantes que são às vezes apresentados para tão poucas pessoas."

No marco dessa curiosidade e vontade de conhecer, parece ter sido de fato difícil escolher entre tantas atividades. Neste sentido, Helena dá o seu depoimento: 
"Ainda na manhã do dia 27, antes da abertura oficial do Congresso, os participantes tiveram a oportunidade de escolher entre dois Espaços de Diálogo, o primeiro começando às 9:30 e o segundo às 11:30. Eram sete temas diferentes distribuídos nas duas sessões. Acabei decidindo começar pelo tema Prácticas colaborativas y dialógicas informadas por el bienestar mental/corporal - una conversación filosófica, conversa facilitada por Sue Levin e Adriana Gil-Wilkerson, ambas do Houston Galveston Institute do Texas, EUA, berço e centro de criação e difusão da abordagem Construcionista Social geradora das práticas dialógicas. No segundo horário escolhi um diálogo coordenado por Pavel Nepulstil: Abrazando nuestros hábitos: Prácticas dialógicas colaborativas en la adicción y la recuperación. Foi uma atividade surpreendente e também muito interessante em que, através de um exercício experiencial, analisamos o contexto e o significado de nossos hábitos enfocando formas que podem ajudar a nós e a nossos clientes de terapia a 'abraçar' os hábitos de que gostamos em vez de 'combatê-los', criando novos significados e possibilidades para seguir adiante".

Helena continua seu relato comentando como a abordagem focada em hábitos a remeteu a um texto de Gregory Bateson (1987) em que ele amplia o conceito de inconsciente, descrevendo os aspectos cognitivos da interpretação de imagens e incluindo os hábitos que levam a atitudes e ações automaticamente, sem que haja uma razão consciente para tal. Neste sentido,

“tratar as 'dependências' como hábitos que podem ser trocados mediante atenção e evitação de alguns contextos e aproximação a outros abole o estigma ligado ao 'tratamento de dependência química' e amplia oportunidades de trabalho com hábitos em geral, seja facilitando a criação de hábitos desejados, seja facilitando a diminuição dos indesejados".

Também surpreendente para Helena foi o diálogo com Ann Caunliffe, profissional inglesa da área de administração que dá aulas durante um semestre por ano em São Paulo, na Fundação Getúlio Vargas, e desenvolve práticas reflexivas em organizações e empresas.

“Ann fez uma interessante distinção entre reflexão - uma prática gerada por epistemologia objetivista, isto é, sujeito/s reflete/m sobre um objeto por eles recortado e escolhido; e reflexividade - o/s sujeito/s refletem sobre uma situação da qual são parte, que é como entendemos a reflexão segundo Tom Andersen, e especificou a reflexividade crítica, procedimento semelhante à problematização proposta por Michel Foucault (1966)".

Cecília também destaca os Espaços de Diálogo:

"Busquei participar de Oficinas com temas propostos a partir de contextos de prática diversos daquele que conheço e convivo no dia a dia de meu trabalho na Saúde Mental. Com isso, conheci, por exemplo, um pouco sobre a proposta de integração de práticas dialógicas na Educação Cooperativa, apresentada por Frances García, de Porto Rico; e me 
encantei com o trabalho de Mírian Cediel, da Colômbia, e seu orientador Gerrit Loots, da Bélgica, sobre como transformar vidas através da prática musical em uma orquestra. Mais do que aprender ferramentas específicas para a prática, saí dessas oficinas com a energia e esperança fortalecidas para seguir lidando com os desafios de meus projetos em São Paulo. Foi também uma rica experiência de aprendizado o Workshop facilitado por Leoç Zatloukal, da República Checa, Creative improvisation in therapeutic conversations and development of clients' resources. Surpreendeu-me porque parecia, inicialmente, uma proposta lúdica e leve, mas os diálogos em pequenos grupos foram permitindo constituir uma potente experiência de reflexão a partir das consignas do facilitador da atividade. Uma vivência interessante sobre confiar, escutar, arriscar, inventar e criar conjuntamente".

E Alexandra completa:

"Marcou-me muito a palestra de Ken Gergen, que nos contou que há mais um elemento essencial a ser considerado nas ideias Construcionistas Sociais, a qualidade da relação que estabelecemos com o outro. O foco apenas na linguagem traz o risco de um cognitivismo, como se bastasse apenas mudar a palavra para mudar o nosso entorno. Gergen disse ainda que a forma do vínculo estabelecida numa relação colaborativa é primordial para gerarmos transformações".

As três participantes contam ainda que ficaram impressionadas não apenas com a quantidade - foram vinte brasileiros apresentando seus trabalhos em formato de oficina, espaços de conversa, pôsteres e sessões de "Tad Talks" (apresentações rápidas com slides somente com imagens) - como a qualidade desses trabalhos. Helena participou de uma dessas sessões, apresentando o projeto "Jovem Solidário", que vem sendo desenvolvido em parceria com Paula Ayub (psicóloga e terapeuta de família de São Paulo que coordena o Centro de Convivência Movimento, voltado para jovens neuroatípicos - como são hoje denominados aqueles que têm transtorno do espectro do autismo TEA). Na sua avaliação, a nossa produção não fica a dever nada às dos demais países. Cecília complementa: "Ao lado do orgulho, fiquei feliz de ter conhecido pessoas com quem seguir conversando no Brasil e continuar aprendendo, ampliando o pertencimento a uma rede que poderá seguir propondo práticas colaborativas para, como propôs Gergen na Plenária de encerramento, 'construir um futuro"'.

Finalizando, Helena, Cecília e Alexandra falam dos desafios a partir do que viveram e sentiram nos três dias do Congresso: "Em termos de desafios, fico com o convite para ampliarmos as práticas colaborativas e dialógicas não só no campo da clínica, mas em todos os serviços humanos"; "a presença da delegação da China me fez ficar curiosa para conhecer (e aprender com) as práticas colaborativas nas diferentes culturas"; "desejo de seguir junto abrindo e mantendo espaços para o diálogo em um mundo melhor para todos". 
Parabenizamos e agradecemos as três participantes por nos terem possibilitado, através de seus ricos relatos e depoimentos, saborear de alguma forma o clima de colaboração, diálogo e amizade desses dias de verão em Brno.

\section{REFERÊNCIAS}

Bateson, G.(1987). Steps to an ecology of mind. New Jersey: Jason Aronson Inc. Foucault, M.(1966). Las palabras y las cosas.Madri: Siglo XXI

\section{LEONORA CORSINI}

Psicóloga, terapeuta de família, mestre em Psicologia (UFRJ) e doutora em Serviço Social (UFRJ). Integra a equipe clínica do Instituto Noos, em São Paulo.

E-mail: corsinileonora@gmail.com

\section{ALEXANDRA DA ROSA MOREIRA}

Psicóloga formada pela Faculdade São Camilo, São Paulo, e pedagoga, graduada pela Universidade Federal de Santa Catarina. Terapeuta de família e casal, fez sua formação no Instituto Noos do Rio de Janeiro. Atualmente, é mestranda no curso de Psicologia na Universidade Católica de Lisboa. Possui Diplomado Internacional em Perspectiva e Prática Profissional Generativa e é pós-graduada em Linguagem/Comunicação e Gestão de Recursos Humanos. Integra, como associada efetiva, a equipe clínica do Instituto Noos em São Paulo e é sócia-titular da Associação Paulista e Brasileira de Terapeutas de Família.

E-mail: alexandramoreira.psicologa@gmail.com

\section{CECÍLIA CRUZ VILLARES}

Terapeuta Ocupacional, mestre em Saúde Mental pela UNIFESP e Terapeuta de Família pelo Instituto Familiae de São Paulo. Trabalhou no Departamento de Psiquiatria da UNIFESP de 1984 a 2017, onde coordenou atividades docentes no Curso de Especialização em Terapia Ocupacional em Saúde Mental, na Residência Multiprofissional em Saúde Mental e no PROESQ - Programa de Esquizofrenia da UNIFESP. É cofundadora da ABRE - Associação Brasileira de Familiares, Amigos e Portadores de Esquizofrenia, onde desenvolve ações de acolhimento e apoio, educação e defesa de direitos em saúde mental. No Instituto Familiae, coordenou o Módulo Família e Transtorno Mental no Curso de Formação de Terapia de Família e Casal, entre 2008 e 2013. Integra, como associada efetiva, a equipe clínica do Instituto Noos em São Paulo.

E-mail: civillares@gmail.com 


\section{HELENA MAFFEI CRUZ}

Socióloga e psicóloga, com formação em psicanálise pelo Instituto Sedes Sapientiae e em terapia familiar pelo Instituto de Terapia de Família do Rio de Janeiro. Mestre em psicologia clínica pela PUC-SP, é terapeuta de adultos, crianças, famílias e casais.

Foi sócia-fundadora, docente e supervisora do Instituto FAMILIAE (1991-2015) e sócia-fundadora da Associação Paulista de Terapia Familiar - APTF (1993), da qual foi secretária da diretoria (1996-1997) e vice-presidente (2000-2001). Coordenadora do grupo de participantes de São Paulo do programa Triângulo Austral para a América Latina, patrocinado pela Universidade de Tromso, Noruega, sob a direção de Tom Andersen (2004-2007). Editora associada da revista Nova Perspectiva Sistêmica desde 2006, tem também contribuído, como autora e organizadora, em livros, capítulos e outras publicações nacionais e internacionais, com destaque para: Família é Quem Cuida de Mim, livro de sua autoria que traz narrativas de identidade de jovens adultos criados em abrigos (2008); Papai, mamãe, você... E eu? Conversações terapêuticas em famílias com crianças (2000); e Me Aprende? (2012) - estes últimos como organizadora. É diretora do Instituto desde 2015. Associada à Faculty do Taos Institute, Texas, EUA.

E-mail: hmcruz@noos.org.br 